Urinary StaINS.

Dr. William Corber (London, E.C.) writes: If Dr. A. H. Skinner of Haukow is a cystoscopist he will fiud that phenol red works guite well if the bladder is distended with a sterile solution of sodium bicarbonate, a drachm to the piut. The most satisfactory dye, however, is indigo carmine 0.4 per cent., $10 \mathrm{c.cm}$. being injected intravenously. This is obtainable in sterile ampoules.

\section{Treatment of Dischezia.}

Dr. R. Macdonald Ladel. (Birmingham) writes in reply to "H. M.": It seems possible that the case might be treated successfully by means of psychotherapy. The desire for local treatment may be a substitution, a gratification which analysis would make clear and remove. If psycho-analysis is not would relieve the symptoms.

\section{INCOME TAX.}

Replacement of Car.

"A. H. L. T." bought a 10/15 " F" car in 1922 for $\$ 575$ and sold it in 1925 for $£ 220$, buying a similar saloon car for $£ 378$; the latter car was not a success and in 1926 he sold it for $\$ 325$, buying a 14/40 " $S$ " saloon for $£ 805$. To what allowances is he entitled?

* * As a professional expense of the year 1925 on the grounds of obsolescence, the out-of-pocket costs-namely, $£ 378-£ 220=£ 158$; also, as an expense of the year 1926, the cost of replacing the unsuccessful car with one of similar make and power-that is, $£ 378-£ 325=£ 53$-the balance of expense represents additional capital outlay. As against the income lax assessment for 1926-27 he should also claim the percentage "depreciation" allowance at 15 or 20 per cent. on $(£ 805-£ 53=) £ 752$. These observations assume that the cars were used for professional purposes only; to the extent that they were otherwise employed the allowances should be restricted.

\section{LETTERS, NOTES, ETC.}

\section{Drug ADDICTs.}

Dr. E. E. DUFTY (Maltby) writes: I agree with Dr. Winter (August 14th, p. 328). Forty-six years ago I was apprenticed to a chemist and during six years we had three customers who took tinctur of opium. I have had forty years in the medical profession and have never seen a drug addict. To me it seems legislation gone mad-something like the prohibition laws in America: faddists and cranks passing vexatious laws because a few degenerates have tried to get a new sensation out of a useless life by taking drugs.

\section{Dry Cupping in Auto-Haemotherapeutics.}

WET and dry cupping have, from time immemorial, been popular methods of treatment, and their popularity is not limited to any one country or indeed to any one civilization, for in one form or another cupping is practised in lands as far apart as France and China, Russia and Arabia. One of the commonest spectacles when travelling in some parts of the Near East is a man with shaven poll sitting patiently in the open air with half a dozen cupping glasses adhering to his scalp. The curious thing is that it should have almost dropped out of practice in Great Britain. Virtues it must have or it would not have maintained its reputation. But how does it act? Putting aside wet cupping, which, after all, is merely blood-letting on a small scale, the action of dry cupping is not easy to define and explain. It is always ary cupping is not easy to define and explain. It is alwass assumed to exert a local decongestive action, hence the cups are
applied over the back of the chest in congestion or inflammation applied over the back of the chest in congestion or inflammation of the lung, over the kidneys in acute nephritis, as also in lumbago. be supposen to exert any action on lungs or kidney. An ingenious explanation has recently been made. To cause blood to be effused in or beneath the skin is much the same thing as withdrawing known as auto-haemotherapy is based. Exactly what autohaemotherapy does is still a matter of doubt, but what autocan be proved to achieve that can fairly be claimed for whatever it A plausible scientific explanation of its action and effects might rehabilitate cupping in daily practice.

Treatment of Tic-Douloureux.

Dr. Florence Theobalds (Buxton) writes: It is known that calcareous deposits are common in the brains of old people, and such a deposit, even if minute, might easily be the cause of neuralgia, by direct pressure or by diminishing the blood supply. mental deterioration, had a typical attack of tic-douloureur. It was most distressing to see her. As her general condition sugasted arterial deseneration, As her general condition acid, the juice of a lemon daily, I prescribed dilute phosphoric acid, the juice of a lemon daily, and warm applications to the face. She had slow but steady relief. Each time the medicine have to be continued indefinitely. But it has been most suc. cessful so far, and she has responded well in other ways to the cessful so far, and she has responded well in other ways to the treatment. Whether the result in these cases is due to an
increased calcium excretion I do not know, but the calcareous increased calcium excretion I do not know, but the calcareous senile dementia suggests that early treatment on these lines should be helpful and preventive.
EfFect of Light on the Vitamin A Content of COD-LIVER OIL.

As the result of experiments in which cod-liver oil stored in air tight bottles made of "Philadelphia oval " flint glass were exposed to diffused light, and in other cases to direct sunlight passing through windows, A. D. Holmes and Madeleiue G. Pigott report in the Boston Medical and Surgical Journal for August 5th that there is evidence that the portion of the sun's spectrum which destroys the vitamin A content of cod-liver oil is not cut out by the type of glass employed in the manufacture of windows and flint bottles. Young albino rats, with well developed experimental vitamin A malnutrition, were used for the feeding tests, and all the investigations were controlled. The authors conclude that coring the storage aud distribution of cod-liver oil it should be kept in cartons or paper wrappers.

Potassium Chlorate in Cancerous Ulceration.

Dr. VALlabhdas N. MeHTA (Viramgam, Bombay Presidency) writes: With reference to Dr. T. M. Allisou's note (BRITISH MEDICAL JOURNAL, l'ebruary 6th, p. 268) regarding the use of potassium chlorate internally in cancerous ulcerations, I have had the occasion to try it in a case of cancer of the tongue where there was extensive ulceration in the floor of the mouth, with severe pain and foul smell from the mouth. 'The patient, a months, and the disease having reached an inoperable stage momething that could relieve the intense suffering was greatly desired by the patient. Potassium chlorate, 10 grains in sweetdesired by the patient. Potassium chlorate, 10 grains in sweettimes a day, greatly relieved the patient's suffering, and now she has practically no pain and no foul smell, and she can take the liquid and semi-solid food with great ease. In this disease, when it bas reached an incurable stage, this treatment acts like magic, and is a great boon to patients suffering from such cancerous
ulcerations. It is well worth a trial, as there is no other known treatment as jet which can do any good in advanced cases.

Nitrous Oxide Anaesthesia: Status Lymphaticus.

Dr. C. Langton HEWER (London, N.W.) writes with reference to the note by Dr. Healey published on August 2lst (p. 343): Babies are so intolerant of oxygen deficiency that it is a matter of considerable difficulty to anaesthetize them satisfactorily with nitrous oxide and oxygen. If we substitute air for oxygen, the difficult task becomes an impossible one. Might I suggest that the "status epilepticus" was in reality asphyxial jactitation? With regard to Dr. Healey's remark that "anaesthetics in very agreement if, by "anaesthetics," he refers to pure nitrous oxide.

\section{Long Cmbilical Cord.}

DR. N. Moxon (Gainsborough) recently attended a woman, aged 40 , in. N. Moxon (Gainsborough) recently attended a woman, aged 40, cord measured 531 in. This is undoubtedly an unusual length, but whether a "record," as Dr. Moxon supposes, we cannot say.

\section{Holidays For Factory Girls.}

WE have received the following letter signed on behalf of the Factory Girls' Country Holiday Fund by the Countess of Sandwich, the Bishop of Kensington, Sir Thomas Barlow, Dr. Mary Scharlieb, Miss Lilian Braithwaite, Dr. Frank Lloyd, and the Rev. Dr. K. F. Norton:

"We venture to ask you to allow us to make an urgent appeal for the Factory Girls' Country Holiday Fund. Our funds are low, and we fear that many who are hoping to go away during the next few weeks will be disappointed of their little holiday this summer unless we have a generous response to this appeal. Several of those who are hoping to go have never slept out of London before. The need for a brief rest aud change is possibly greater this year than it has been for some t.me. rrade depression has resulted in many girls becoming the main support of their families. The health of the community in the crowded and airless districts of London has deteriorated considerably, and this is specially apparent in the women and girls. Nor has it been possible, although many of them have been saving up since the early spring, for them to contribute as much as usual this year towards their holiday. Good food and fresh air for a week or two work a marvellous change, and will make it possible for many to continue their work during the coming winter, and the short holiday gives fresh hope and courage. Subscriptions and donations will be thankfully reby Miss Canney, 75, Lamb's Conduit Street, W.C.1.;"

\section{Erratum.}

Iv the note on the treatment of tuberculosis in Lancashire on page 357 of the Journal for August 21st, it should have been stated that twenty-four, and not fourteen, dispensaries are now in operation.

Vacanctes.

Notrficatrons of offices vacant in universities, medical colleges, and of vacant resident and other appointments at hospitals, will be found at pages $32,33,37,38$, and 39 of our advertisement columns, and advertisements as to partnerships, assistantships, and locumtenencies at pages 34 and 35 .

A short summary of vacant posts notifled in the advertisement columns appears in the Supplement at page 140 . 